\title{
Etude de la dégradabilité enzymatique des aliments concentrés et sous-produits
}

\author{
A. CAStagna, D. SAUVANT, Michelle DORLEANS et Sylvic GIGER \\ I.N.R.A., Laboratoire de Recherches de la Chaire de Zootechnie \\ Institut national agronomique Paris-Grignon \\ 16, rue Claude-Bernard, F 75231 Paris Cedex 05
}

\begin{abstract}
Résumé
Une méthode de mesure de dégradabilité enzymatique applicable aux aliments concentrés a été mise au point en simplifiant au maximum la méthode de travail. La technique proposéc comprend trois étapes principales : un empesage - l'action d'un mélange de préparations glucolytiques (amylase, cellulase, hémicellulase) et une attaque à la pepsinechlorhydrique. Pour 37 aliments divers $(2,8 \leqslant$ cellulose brute $\leqslant 48,3$ p. 100 MS) ayant fait l'objet d'une mesure de digestibilité in vivo de la matière organique $(30,7 \leqslant$ CUD mo $\leqslant$ 92,3 p. 100), la dégradabilité enzymatique permet de mieux prévoir le CUDmo que les teneurs en cellulose brute, NDF, ADF et ADLignine considérées séparément. La même observation peut être faite lorsque les 18 aliments concentrés sont considérés séparément. La combinaison des teneurs en NDF et ADLignine permet d'aboutir à une précision comparable de prédiction de la dégradabilité enzymatique pour les 37 (ETR $=4,84$ p. 100 vs 4,97 p. 100) ou les 18 (ETR $=3,44$ vs 3,32) aliments cités. Pour les 11 aliments composés considérés, la teneur en ADLignine aboutit à une meilleure prévision que la dégradabilité enzymatique (ETR = $2,06$ vs $3,29 \mathrm{p}, 100)$. La méthode proposée a fait l'objet d'une chaîne analytique dans le cadre de la C.E.E.
\end{abstract}

Mots clés : Dégradabilité enzymatique, aliments concentrés, sous-produits, prévision diges:ibilité ruminant, analyse Van Soest.

\section{Introduction}

Les méthodes de prévision de la digestibilité des aliments des ruminants peuvent utiliser des réstultats issus d'analyses chimiques, de mesures physiques (énergie de broyage, réflectance dans l'infra-rouge...) ou de tests de dégradabilité in vitro. Ces tests sont réalisés, soit par incubation dans du jus de rumen, comme dans la méthode de Tilley \& TerRy (1963), soit par mesure de la dégradabilité de l'aliment en présence de préparations enzymatiques, de cellulases en particulier.

Le premier essai publié de mesure de dégradabilité enzymatique d'aliments concerne les travaux de Donefer et al. (1963). Depuis, différentes variantes métho- 
dologiques ont été proposées. Certains auteurs ont conçu des méthodes où la préparation cellulasique agit sur des résidus issus d'un traitement par voie chimique de l'échantillon (Mc Queen \& van Soest, 1975 ; Roughan \& Holland, 1977 ; Kellner \& Kirchgessner, 1977 ; Israelsen, Rexen \& Thomsen, 1978 ; Abe, Hori \& Kameoisa, 1979). Enfin, dans d'autres cas, l'action de la cellulase est précédée (Jones \& HAYWARD, 1973 et 1975 ; Goto \& Minson, 1977 ; Allison \& Borzucki, 1978) ou suivie (DoneFer et al., 1963 ; Guggolz et al., 1971 ; Mc QueEn \& van SOEST, 1975 ; Kellner \& KirChGESSNER, 1977) par d'autres traitements enzymatiques généralement protéolytiques.

Les méthodes publiées jusqu'à présent concernent presque uniquement des fourrages; or, les résultats de tests de dégradabilité enzymatique sur les aliments concentrés pourraient permettre de prévoir de manière assez fiable la digestibilité de leur matière organique, donc leur valeur énergétique.

Les aliments concentrés soulèvent des problèmes méthodologiques spécifiques par rapport aux fourrages en raison, notamment, de la variabilité importante des proportions respectives des constituants pariétaux (SAUVANT, 1981) et, de la présence éventuelle de teneurs élevées en protéines, amidon et lipides. L'étude de la dégradabilité enzymatique des aliments riches en amidon a été abordée suivant deux approches différentes. Clark \& Beard (1977) pour des céréales, et Abe, Horil \& Kameoka (1979) pour de l'ensilage de maïs, ont proposé de faire agir des préparations amylasiques. ISRAELSEN, REXEN \& THOMSEN (1978) ont réalisé une attaque cellulasique après un traitement au détergent neutre (van SoEst \& WINE, 1967) d'aliments composés contenant des proportions variables d'orge, de tourteaux de soja et de coton, de mélasse et de paille traitée ou non à la soude. Cependant, avec des aliments riches en amidon, comme les céréales, l'obtention du résidu N.D.F. nécessite un traitement enzymatique par une amylase (ROBERTSON \& VAN SoEST, 1977), ce qui alourdit la méthode initiale et ne garantit pas la disparition totale de l'amidon.

Le présent travail a été entrepris pour évaluer l'intérêt de l'utilisation d'une méthode de prévision de la digestibilité des aliments des ruminants, concentrés et sous-produits en particulier, qui soit basée le plus possible sur des mesures de solubilisation enzymatique. En outre, pour respecter un objectif pratique, une simplification maximale de la méthodologie a été systématiquement recherchée; a priori, toute opération de transvasement est exclue et, dans la mesure du possible, plusieurs enzymes sont associées dans une même incubation.

\section{Matériel et méthodes}

\section{A. Choix des préparations enzymatiques}

De nombreuses préparations enzymatiques sont disponibles sur le marché. Un choix a donc été effectué pour ne retenir que les préparations les plus fréquemment citées dans la bibliographie ou bien celles qui présentent le maximum de garantie de constance dans les livraisons. En outre, les préparations enzymatiques glucolytiques 
ont été choisies de manière à pouvoir être utilisées dans les mêmes conditions au sein d'un seul mélange. Six préparations d'enzymes ont été retenues pour ces essais :

— une pepsine (Sigma $P$ 7012) utilisée à $39^{\circ} \mathrm{C}$ à une concentration de $2,0 \mathrm{~g} / 1$ pendant différentes durées d'action dans l'acide chlorhydrique $1 \mathrm{~N}$. La normalité la plus fréquemment utilisée pour $\mathrm{HCl}$ est $0,1 \mathrm{~N}$, cependant les travaux récents d'ANDrieu (1979) et Aufrere (1982) ont montré l'intérêt de l'utilisation d'une normalité de 1,0 ;

- une pronase (Sigma P 5005) utilisée à 2,0 g/1 dans un tampon phosphate $0,066 \mathrm{M}$ à $\mathrm{pH} 7,4$ et à $39^{\circ} \mathrm{C}$ (ABE, Hori \& KAMEOKA, 1979) : différentes durées d'action ont été testées ;

- une cellulase (Novo, SP 122) de Trichoderma viride à différentes concentrations agissant pendant 24 heures à $39^{\circ} \mathrm{C}$ dans un tampon acide acétique-acétate de sodium 0,05 M à pH 4,7 (ABE, HorII \& KAMEOKA, 1979). D'autres auteurs ont déjà utilisé ce type de tampon pour l'action de cellulases (JARRIGE \& ThIVEND, 1969 ; Mc Queen \& van Soest, 1974 ; Kellner \& Kirchgessner, 1977 ; Goto \& Minson, 1977 ; ANDrIEU, 1979 ; Aufrere, 1982) ;

- une hémicellulase (Novo) d'Aspergillus sp. utilisée dans les mêmes conditions que la cellulase et testée aux mêmes concentrations;

- une amylase (Sigma A 6505 type III A) de Bacillus subtilis utilisée en solution à $0,8 \mathrm{~g} / 1$ en présence d'un tampon acide acétique-acétate de sodium $0,05 \mathrm{M}$ à $\mathrm{pH} 4,7$ pendant 24 heures à $39^{\circ} \mathrm{C}$;

- une amylase (Sigma A 1278 type X1 A) de Bacillus subtilis utilisée dans les mêmes conditions que l'amylase A 6505.

Lorsque des préparations amylasiques sont utilisées, seules ou en mélange, l'échantillon subit un prétraitement par empesage préalable de $10 \mathrm{mn}$ à $70^{\circ} \mathrm{C}$.

\section{B. Choix des matières premières}

Des échantillons de douze matières premières différentes ont été retenus pour les tests de dégradabilité. Le choix de ces aliments a été effectué avec l'objectif de respecter, dans la mesure du possible, les principes suivants :

- être d'un emploi fréquent ;

- être bien connu quant à la digestibiltié in vivo la plus probable de la matière organique ;

- être représentatif des familles végétales et des principaux «types " d'ingrédients utilisés en alimentation animale : riches en amidon (maïs, orge, manioc, son), en protéines (tourteaux de soja, arachide, colza, coprah), en cellulose facilement digestible (pulpe de betteraves, coques de soja) ou en cellulose peu digestible (luzerne déshydratée, paille de blé).

Les caractéristiques analytiques de ces douze matières premières sont indiquées dans le tableau 1. Dans ce premier tableau, figurent également les valeurs moyennes de teneur en cellulose brute et de digestibilité in vivo de la M.O. proposées pour ces aliments dans les tables I.N.R.A. 1978 (Demarouilly, Andrieu \& Sauvant, 1978). 


\section{Mode d'expression des résultats}

Les résultats de dégradabilité sont exprimés en matière organique par rapport à la matière sèche ou la matière organique de l'échantillon de départ :

$$
\begin{aligned}
& \text { D.E.M.S. }=1-\frac{\text { M.S.r }- \text { M.M. } r}{\text { M.S.e }} \\
& \text { D.E.M.O. }=1-\frac{\text { M.S.r }- \text { M.M. r }}{\text { M.S.e - M.M.e }}
\end{aligned}
$$

avec :

M.S.e : quantité de matière sèche de l'échantillon de départ,

M.M.e : quantité de cendres de l'échantillon de départ,

M.S.r : quantité résiduelle de matière sèche,

M.M.r : quantité résiduelle de cendres.

Les données obtenues sont multipliées par 100 pour exprimer les résultats en pourcentage. Les résultats révèlent une corrélation très élevée entre ces deux modes d'expression de la dégradabilité. Pour mettre en évidence les effets spécifiques des préparations enzymatiques, il est tenu compte de la solubilisation de l'aliment par la solution tampon seule. Parmi ces quatre différents modes d'expression des résultats calculés systématiquement, la dégradabilité rapportée à la matière sèche dans l'ensemble enzyme + tampon a été retenue pour ne pas alourdir le texte et pour être cohérent avec la recherche d'une simplification maximale de la méthode.

Tous les résultats cités correspondent à trois répétitions de la même mesure.

\section{Plan de travail}

Les trois familles d'enzymes ont été considérées successivement en trois étapes. Au sein de chaque famille, les préparations ont d'abord été étudiées séparément dans le but d'être comparées les unes aux autres ou bien pour en préciser les conditions d'utilisation. Ces préparations ont ensuite été étudiées en association avec celles des familles préalablement étudiées : cellulase + hémicellulase pour les préparations amylasiques, cellulase + hémicellulase + amylase pour les préparations protéasiques.

Les échantillons utilisés ont été broyés à la grille "classique " de $1 \mathrm{~mm}$, méthode appliquée pour les analyses d'aliments.

\section{Résultats et discussion}

\section{A. Composition des matières premières}

Le tableau 1 montre que les échantillons étudiés présentent des teneurs en cellulose brute qui sont dans l'ensemble très proches des valeurs moyennes proposées 


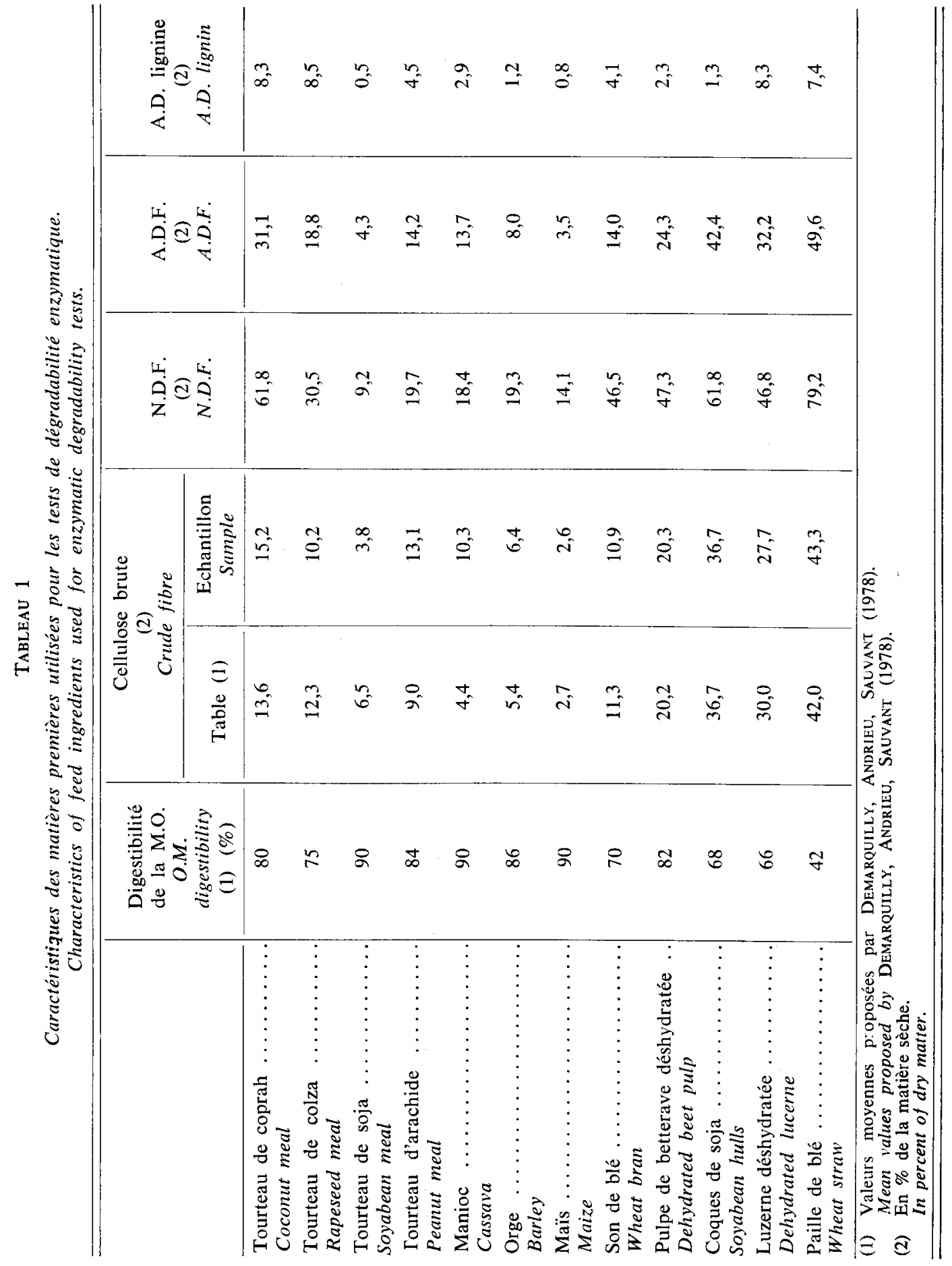


dans les tables I.N.R.A. (Demarouilly, Andrieu \& Sauvant, 1978). Il est, de ce fait, logique d'adopter, comme estimation de la digestibilité la plus probable de la M.O. de ces aliments, les valeurs citées par ces tables.

\section{B. Etude des enzymes dégradant les glucides pariétaux}

\section{Actions séparées de la cellulase et de l'hémicellulase}

ISRAELSEN, REXEN \& THOMSEN (1978) ont montré que l'action d'une préparation cellulasique était pratiquement terminée au bout de 20 heures. La durée d'incubation de 24 heures, qui a déjà été appliquée par différents auteurs (JARRIGE \& THIVEND, 1969 ; Kellner \& Kirchgessner, 1977) a donc été retenue pour les essais d'enzymes glucolytiques; une durée d'action plus longue nécessiterait, en outre, l'emploi d'un agent anti-microbien tel que le nitrure de sodium (Jarrige \& Thivend, 1969).

Comme la bibliographie ne fournit pas une information homogène sur la concentration en enzyme des préparations cellulasiques utilisées, différentes concentrations ont été testées sur $0,5 \mathrm{~g}$ d'échantillon de sept matières premières pour une durée d'incubation de 24 heures à $39^{\circ} \mathrm{C}$. Les figures 1 et 2 (cf. p. 276) présentent les niveaux de dégradabilité des aliments, sous l'action des enzymes et du tampon acide acétique-acétate de sodium en fonction des concentrations testées en cellulase et hémicellulase.

L'accroissement de la dose de l'enzyme augmente le niveau de dégradation des aliments. D'après les valeurs moyennes, le «plateau " est atteint pour les concentrations $1,0 \mathrm{~g} / 1$ et $1,5 \mathrm{~g} / 1$ environ de cellulase et d'hémicellulase respectivement. Cependant, les réponses diffèrent largement d'une matière première à l'autre ; pour la cellulase le «plateau» de la réponse est approximativement atteint pour la concentration de $0,5 \mathrm{~g} / 1$ pour la pulpe de betteraves et de $1,5 \mathrm{~g} / \mathrm{l}$ pour l'orge et le tourteau de colza. Par contre, pour les concentrations étudiées, l'apparition du « plateau » n'est pas évident pour le tourteau de coprah et la pellicule de soja.

La hiérarchie des niveaux de dégradation des ingrédients est comparable entre les deux enzymes. En outre, à concentration comparable en enzyme, la dégradabilité est plus faible avec l'hémicellulase qu'avec la cellulase sauf dans le cas du tourteau de coprah. Cependant, la hiérarchie de la dégradabilité des matières premières sous l'effet de la cellulase ou de l'hémicellulase est très éloignée de leur classement selon leur valeur moyenne de digestibilité in vivo (tabl. 1). Ainsi, l'orge et le manioc présentent-ils une valeur de dégradabilité légèrement inférieure à leur digestibilité ; par contre, les autres matières premières testées, en particulier le tourteau de soja, sont très peu dégradables sous l'effet de la cellulase ou de l'hémicellulase en comparaison de leur digestibilité in vivo. Ces résultats montrent l'insuffisance de l'utilisation unique d'enzymes dégradant les constituants pariétaux dans le cas des aliments concentrés.

Pour ces raisons, le choix des différentes concentrations en enzyme ne pouvait être effectué sur la base de la corrélation avec la digestibilité in vivo la plus probable. Pour différentes concentrations supérieures ou égales aux seuils de $1,0 \mathrm{~g} / 1$ de cellulase et $1,5 \mathrm{~g} / 1$ d'hémicellulase, les deux enzymes aboutissent à un "plateau * et à des résultats de dégradabilité très corrélés $(0,94 \leqslant R \leqslant 0,96, n=7)$, de ce fait, 
DÉGRADABILITÉ ENZYMATIQUE DES ALIMENTS

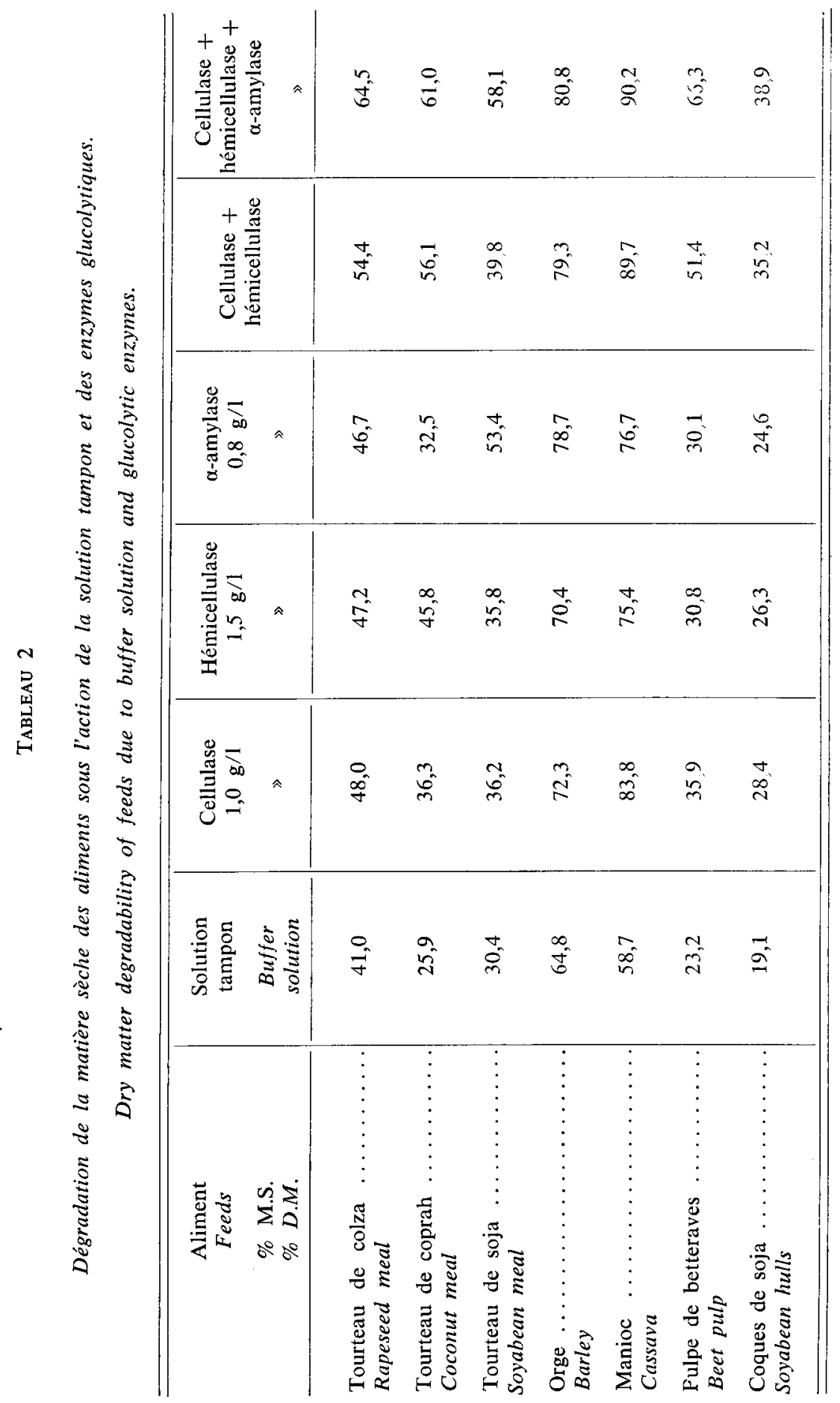


ces deux concentrations en enzyme ont été retenues dans la suite de l'étude. Les concentrations se situent dans la plage de variation observée dans la bibliographie $0,25 \mathrm{~g} / \mathrm{l}$ (Goto \& Minson, 1977) à $1,8 \mathrm{~g} / 1$ (Kellner \& Kirchgessner, 1977).

\section{Etude de l'additivité des effets}

Les deux enzymes dégradant les glucides pariétaux ont été considérées sans l'utilisation de prétraitement. Pour tester l'additivité des effets de ces enzymes, une analyse de variance a été appliquée aux résultats de dégradabilité obtenus selon les quatre combinaisons d'un plan factoriel $2 \times 2$, dans lequel les sept aliments constituent des blocs :

- tampon seul,

- tampon $+1,0 \mathrm{~g} /$ de cellulase,

- tampon $+1,0 \mathrm{~g} / 1$ d'hémicellulase,

- tampon $+1,0 \mathrm{~g} / 1$ de cellulase $+1,5 \mathrm{~g} / 1 \mathrm{~d}$ 'hémicellulase.

\section{Tableau 3}

Dégradabilité de la matière sèche des aliments sous l'action des enzymes glucolytiques (1). Dry matter degradability of feeds due to glucolytic enzymes (1).

\begin{tabular}{|c|c|c|c|c|c|}
\hline $\begin{array}{l}\text { Aliments } \\
\text { Feeds }\end{array}$ & $\begin{array}{c}\text { Cellulase } \\
1,0 \mathrm{~g} / 1 \\
\gg\end{array}$ & $\begin{array}{c}\text { Hémi- } \\
\text { cellulase } \\
1,5 \mathrm{~g} / 1 \\
»\end{array}$ & $\begin{array}{c}\alpha \text {-amylase } \\
0,8 \mathrm{~g} / 1 \\
»\end{array}$ & $\begin{array}{c}\text { cellulase }+ \\
\text { hémi- } \\
\text { cellulase } \\
»\end{array}$ & $\begin{array}{c}\text { Cellulase }+ \\
\text { hémi- } \\
\text { cellulase }+ \\
\alpha \text {-amylase } \\
»\end{array}$ \\
\hline $\begin{array}{l}\text { Tourteau de colza } \\
\text { Rapeseed meal }\end{array}$ & 7,0 & 6,2 & 5,7 & 13,4 & 23,5 \\
\hline $\begin{array}{l}\text { Tourteau de coprah } \\
\text { Coconut meal }\end{array}$ & 10,4 & 19,9 & 6,6 & 30,2 & 35,1 \\
\hline $\begin{array}{l}\text { Tourteau de soja } \\
\text { Soyabean meal }\end{array}$ & 5,8 & 5,4 & 23,0 & 9,4 & 37,7 \\
\hline$\underset{\text { Barley }}{\text { Orge }} \ldots \ldots \ldots \ldots$ & 9,8 & 5,6 & 13,9 & 14,5 & 16,0 \\
\hline $\begin{array}{l}\text { Manioc } \\
\text { Cassava }\end{array}$ & 25,0 & 16,7 & 18,0 & 31,0 & 31,5 \\
\hline $\begin{array}{l}\text { Pulpe de betteraves } \\
\text { Beet pulp }\end{array}$ & 16,1 & 7,6 & 6,9 & 28,2 & 43,1 \\
\hline $\begin{array}{l}\text { Coques de soja } \ldots \\
\text { Soyabean hulls }\end{array}$ & 11,6 & 7,2 & 5,5 & 16,1 & 19,8 \\
\hline
\end{tabular}

(1) Résultats du tableau 2 corrigés par la quantité de matière organique solubilisée par la solution tampon seule.

Results of table 2 corrected for the organic matter content solubilized by the buffer solution. 
Les résultats de ces analyses, résumés dans les tableaux 2 et 3 révèlent l'influence significative des enzymes et des aliments; ils indiquent, en outre, que l'interaction entre les enzymes n'est pas significative. De plus, une relation inter-aliment étroite $(\mathrm{R}=0,91)$ associe les valeurs mesurées de dégradabilité pour le mélange de deux enzymes et les valeurs qui peuvent être prédites à partir des actions de ces deux enzymes utilisées séparément.

Ces résultats démontrent l'additivité des effets des deux préparations enzymatiques considérées, ils indiquent, en outre, que, mis à part le cas du manioc, la dégradabilité des aliments sur l'action du mélange cellulase + hémicellulase (tabl. 3) est approximativement proportionnelle à leur teneur en paroi végétale (tabl. 1).

\section{Etude de la combinaison des enzymes glucolytiques}

\section{Effets séparés des amylases}

L'étude de ces effets séparés a été conduite sur quatre matières premières préalablement empesées pendant $10 \mathrm{mn}$ à $70^{\circ} \mathrm{C}$ : deux riches en amidon, le maïs et l'orge et deux n'en contenant pas ou très peu, les tourteaux de colza et de soja.

Les résultats indiquent que, dans les conditions décrites, 1' $\alpha$-amylase A 6505 dissout significativement plus la matière organique des aliments que l'amylase A 1278 (tabl. 4). En outre, l'interaction significative enzyme $\times$ aliment montre que les différences de sensibilité aux deux enzymes ne sont pas identiques pour les quatre aliments. Ainsi, le maïs présente la même dégradabilité vis-à-vis des deux enzymes alors que l'orge est plus sensible à l'amylase A 6505. Les valeurs de dégradabilité observées pour les tourteaux de colza et de soja traduisent vraisemblablement l'impureté des enzymes utilisées qui présentent de ce fait une activité de type protéolytique et/ou cellulolytique.

\section{Tableau 4}

Comparaison de la dégradabilité de quatre aliments sous l'action des amylases $A 6505$ et $A 1278$ (1).

Comparison between the degradability of four feeds by amylases $A 6505$ and $A 1278$ (1).

\begin{tabular}{|c|c|c|}
\hline $\begin{array}{l}\text { Aliments } \\
\text { Feeds }\end{array}$ & $\begin{array}{l}\text { Amylase } \\
\text { A } 6505\end{array}$ & $\begin{array}{l}\text { Amylase } \\
\text { A } 1278\end{array}$ \\
\hline$\underset{\text { Barley }}{\text { Orge }} \ldots \ldots \cdots \cdots \cdots \cdots$ & 78,7 & 73,8 \\
\hline$\underset{\text { Maize }}{\text { Maïs }} \ldots \ldots \ldots \ldots \ldots \ldots \ldots \ldots$ & 60,5 & 59,9 \\
\hline $\begin{array}{l}\text { Tourteau de colza } \ldots \ldots \ldots \ldots \ldots \ldots \ldots \ldots \ldots \ldots \ldots \\
\text { Rapeseed meal }\end{array}$ & 46,7 & 41,4 \\
\hline $\begin{array}{l}\text { Tourteau de soja } \ldots \ldots \\
\text { Soyabean meal }\end{array}$ & 53,4 & 39,4 \\
\hline
\end{tabular}

(1) Les différences entre les enzymes et les aliments sont hautement significatives $(P<0,01)$, de même que l'interaction aliment $X$ enzyme.

Differences between enzymes and feeds are highly significant $(P<0.01)$ as the feed $\times$ 'enzyme interaction. 


\section{$\therefore$ Coniparaison des deux amylases avec un mélange cellulase + hémicellulase}

L.c. cirnylases A 6505 et A 1278 ont été comparées en combinaison avec le n: o cchulase - hémicellulase sur des échantillons préalablement empesés. L'anaO c cásticuc des résultats, rapportés dans le tableau 5 , révèle une action, en A. : inificaticment plus faible pour l' $\alpha$-amylase A 1278, ainsi qu'une interc....... $:$ aliment. En outre, la comparaison des résultats des tableaux 4 et 5 IF...... a ic lascociation des amylases avec le mélange cellulase + hémicellulase ...... . i unc cissoluticn accrue de la matière organique pour l'orge et les deux a c........ ... oincire pour le maïs qui est alors beaucoup moins dégradé que

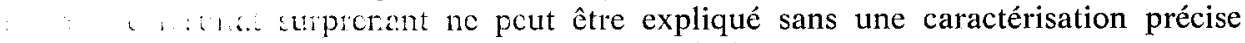

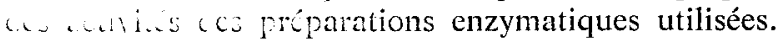

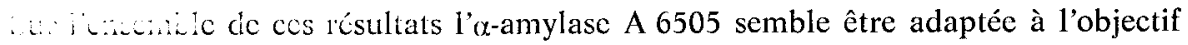
- un ri.izcn cic son activité supérieure.

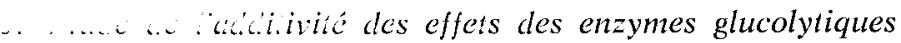

¿...... ćc l'smylasc A 6505 a été considéré avec celui du mélange cellulase scion les quatre combinaisons d'un plan factoriel de type $2 \times 2$, ....ikitcricnt empesés constituent des blocs :

…...... scut, Cólange (ccllulase + hémicellulase), -amylase A 6505, ..-:risylace + mélange (cellulase + hémicellulase).

aur sont très significatifs et il n'y a pas d'interaction entre les - ytraticucs considérées (tabl. 2). Il y a par contre une inter- naymc x alinent causée par le fait que l'action du mélange des . . $\mathrm{ct}$ le manicc est nettement plus faible, 12,4 et 17,5 points ... $\quad .<C$ i n puvait attendre à partir des dégradabilités observées .... Ln co l'anylase et du mélange cellulase + hémicellulase. Les ......... concernées sont les plus riches en amidon et les plus solu................... cen seul (tabl. 2). Les effets observés pourraient traduire ¿.. Ch.c dics sfectres d'activité des deux types de préparations .. Los résultats observés pour ces deux matières premières ne $\because:$ i is caracteristiques des aliments riches en amidon, les données ...........s cn sont la preuve (tabl. 5).

c.uico co colubilisation sous l'action de l'empesage, du tampon c: comyncs gilucolytiques sont, excepté pour le manioc et l'orge, $\therefore c=$ ( $\vdots 3$ à 30 points) aux valeurs les plus probables de digestibilité ... Nic crgenique. 


\section{Tableau 5}

Comparaison de la dégradabilité de quatre aliments s:ust. $l \cdot{ }^{\prime}$

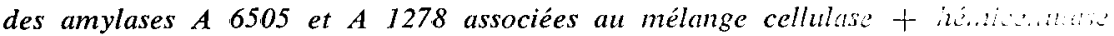

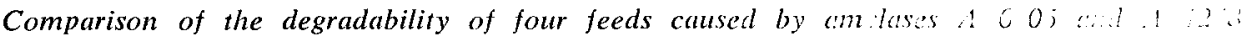
associated with the cellulase + hemicellulasc mintme.

\begin{tabular}{|c|c|c|}
\hline $\begin{array}{l}\text { Aliments } \\
\text { Feeds }\end{array}$ & $\begin{array}{c}\text { Amylase A } 6505 \\
+ \text { cellulase } \\
\text { + hémicellulaso } \\
\Rightarrow\end{array}$ & 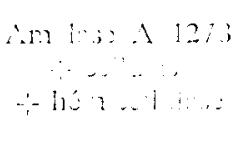 \\
\hline $\begin{array}{l}\text { Orge } \ldots \ldots \ldots \ldots \ldots \ldots \ldots \ldots \ldots \ldots \\
\text { Barley }\end{array}$ & 808 & 81.1 \\
\hline $\begin{array}{l}\text { Maïs } \\
\text { Maize }\end{array}$ & 53,0 & $\therefore 21$ \\
\hline $\begin{array}{l}\text { Tourteau de colza } \ldots \ldots \ldots \ldots \ldots \ldots \\
\text { Rapeseed meal }\end{array}$ & 64,5 & $52 \therefore$ \\
\hline $\begin{array}{l}\text { Tourteau de soja } \ldots \ldots \ldots \ldots \ldots \ldots \\
\text { Soyabean meal }\end{array}$ & 58,1 & 439 \\
\hline
\end{tabular}

(1) Les différences entre les amylases et les aliments sont hautemsat si, l...... de même que l'interaction aliment $X$ enzyme.

Differences between amylases and feeds are highly significant $(P<0.01)$ (s) $h$, : : interaction.

D. Etude des combinaisons entre les préparations glucolytiq:io et protéolytique

Les différences importantes entre les conditions d'utilisation des pasaratias glucolytique et protéolytique nécessitent de procéder à des incubations séparíci you: pouvoir utiliser les différentes enzymes à des niveaux d'activité quil soicnt loj $7,0,3$ proches possible de leur optimum. Donefer et al. (1963) ont d'aillcurs cbrow l'activité de la pepsine, ajoutée à une incubation cellulasique était réduite cn wisen du $\mathrm{pH}$ trop élevé du milieu.

\section{Influence de la durée d'hydrolyse}

Différents temps d'hydrolyse ont été testés pour la pepsine et la pronase. 2 'o: tif de l'utilisation de ces préparations enzymatiques est de contribucr à la com des contenus cellulaires par hydrolyse des fractions protéiques. La papian e! th

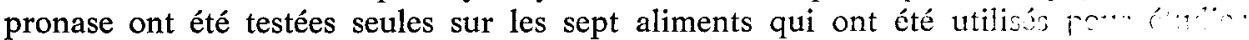
l'influence des concentrations en cellulase et hémicellulase (cf. fig. 1 ct 2). Le tableau 6 indique que la solubilisation de la matière sèche de ces alimen. "? "? pronase ne varie pas entre 1 et 15 heures d'incubation. Par contre, la solubinsaion 
s'accroît dans la même période sous l'action de la pepsine-chlorhydrique. L'augmentation de la solubilisation est plus marquée pour les coques de soja et surtout les pulpes de betteraves (tabl. 6), ce qui traduit vraisemblablement la solubilisation des hémicelluloses sous l'effet du $\mathrm{pH}$.

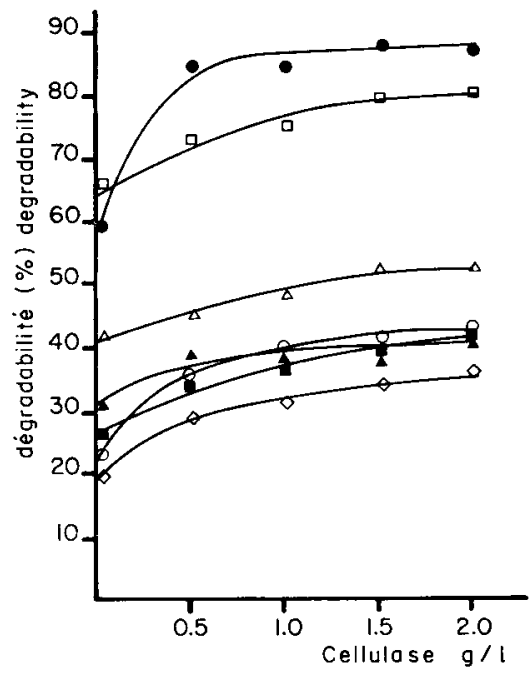

FIG. 1

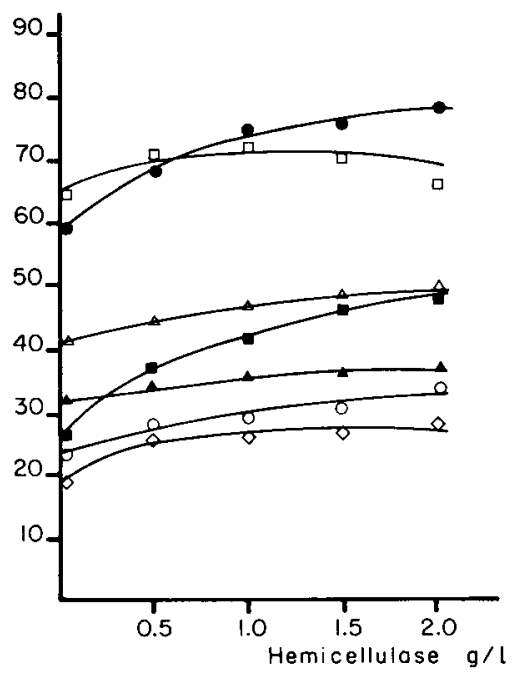

FIG. 2

FIG. 1

Influence de la concentration en cellulase sur la dégradabilité des aliments. Influence of cellulase concentration on feed degradability.

FIG. 2

Influence de la concentration en hémicellulase sur la dégradabilité des aliments. Influence of hemicellulase concentration on feed degradability.

- Manioc - Cassava.

$\square \quad$ Orge - Barley.

$\triangle$ Tourteau de colza - Rapeseed meal.

- Tourteau de coprah - Coconut meal.

- Tourteau de soja - Soyabean meal.

O Pulpes de betteraves - Sugarbeet pulp.

$\theta$ Coques de soja - Soyabean hulls.

Les valeurs de solubilisation sont moyennement corrélées à celles de la digestibilité probable de la M.O., avec un léger avantage pour la pepsine : $0,55<\mathrm{R}<0,64$ contre $0,46<\mathrm{R}<0,52$ pour la pronase. D'autre part, au-delà de 4 heures, les valeurs de solubilisation sous l'effet de la pepsine- $\mathrm{HCl}$ présentent avec les teneurs en NDF et ADF des aliments des valeurs de corrélation plus proches de -1 que dans le cas de la pronase. 
Tableau 6

Influence de la durée d'hydrolyse à la pepsine et à la pronase sur la dégradabilité de la M.S. des aliments.

Influence of the hydrolysis time with pepsin and pronase on the D.M. degradability of feeds.

\begin{tabular}{|c|c|c|c|c|c|c|}
\hline & \multirow{2}{*}{$\begin{array}{l}\text { Enzyme } \\
\text { (1) }\end{array}$} & \multicolumn{5}{|c|}{$\begin{array}{l}\text { Temps d'hydrolyse } \\
\text { Hydrolysis time }\end{array}$} \\
\hline & & 1 & 2 & 4 & 6 & 15 \\
\hline Tourteau de colza & $\mathrm{e}$ & 64,6 & 65,4 & 66,9 & 66,1 & 67,8 \\
\hline Rapeseed meal & o & 62,4 & 59,9 & 61,1 & 61,6 & 62,0 \\
\hline Tourteau de coprah & $\mathrm{e}$ & 46,9 & 45,7 & 47,0 & 46,9 & 48,8 \\
\hline Coconut meal & o & 48,3 & 47,4 & 48,6 & 48,5 & 48,6 \\
\hline Tourteau de soja .. & $\mathrm{c}$ & 820 & 83,3 & 83,8 & 85,2 & 87,3 \\
\hline Soyabean meal & o & 81,0 & 80,7 & 81,1 & 83,2 & 81,2 \\
\hline Tourteau d'arachide & $\mathrm{e}$ & 70,6 & 72,9 & 70,6 & 71,3 & 74,4 \\
\hline Peanut meal & o & 69,9 & 69,7 & 69,6 & 68,6 & 66,4 \\
\hline Pulpe de betterave & $\mathrm{c}$ & 42,2 & 47,0 & 52,0 & 55,6 & 59,8 \\
\hline Beet pulp & o & 33,4 & 35,8 & 35,5 & 36,9 & 38,7 \\
\hline Coques de soja & e & 26,4 & 27,6 & 29,9 & 32,2 & 33,1 \\
\hline Soyabean hulls & o & 24,5 & 25,2 & 24,8 & 27,1 & 26,4 \\
\hline Luzerne déshydratée . & $\mathrm{e}$ & 44,0 & 46,1 & 46,2 & 45,8 & 48,6 \\
\hline Dehydrated lucerne & o & 45,3 & 46,1 & 45,6 & 46,8 & 45,8 \\
\hline (1) $\begin{array}{l}\mathrm{e}=\text { pepsine } \\
\mathrm{o}=\text { pronase }\end{array}$ & & & & & & \\
\hline
\end{tabular}

\section{Etude des combinaisons avec les enzymes glucolytiques}

Plusieurs séries de mesures de dégradabilité ont été réalisées sur les douze matières premières du tableau 1 pour comparer différentes séquences d'action des préparations glucolytique (mélange cellulase + hémicellulase + amylase) et protéolytique (pepsine ou pronase). La comparaison entre les quatre séquences a porté sur deux groupes de paramètres : le premier groupe comprend la valeur du coefficient de corrélation entre la dégradabilité observée et la valeur de la digestibilité moyenne in vivo, de la matière organique retenue dans les tables I.N.R.A. 1978 (tabl. 7) ainsi que l'écart-type résiduel de cette relation, et, le second groupe la répétabilité intra aliment du résultat.

Les résultats obtenus, rapportés dans le tableau 7, montrent que les différentes séquences considérées aboutissent à des hiérarchies des valeurs de dégradabilité proches des valeurs de digestibilité probable de ces aliments, ce qui n'était pas le cas 
A. CASTAGNA et al.

\section{Tableau 7}

Vuriation de la dégradabilité de la matière sèche des aliments en fonction de différentes séquences d'attaques enzymatiques.

Variation in the dry matter degradability of feeds ('s a fanction of different sequences of enzymatic attacks.

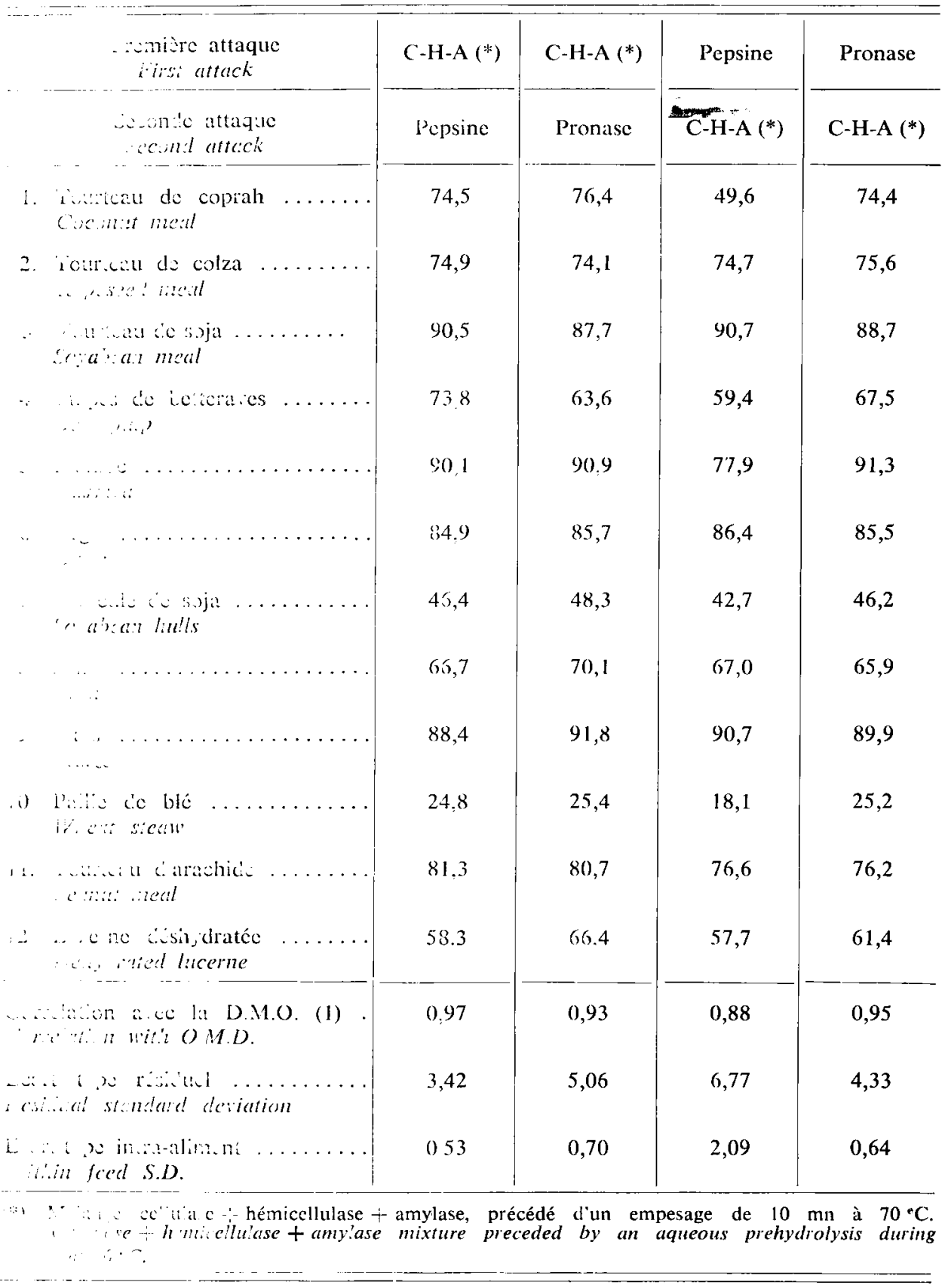


lorsque les préparations glucolytiques étaient appliquées seules (tabl. 2 et 5). L'action préalable de la pepsine aboutit aux résultats les plus médiocres pour les paramètres considérés. En outre, cette séquence aboutit à des valeurs de dégradabilité qui sont en moyenne de cinq points inférieures aux trois autres. Cet écart est particulièrement marqué pour le tourteau de coprah, la pulpe de betteraves, le manioc et la paille (tabl. 7). Ces résultats pourraient provenir d'un lavage insuffisant du résidu de l'attaque pepsique. Kellner \& Kirchgessner (1976) ont remarqué la nécessité de procéder à un lavage rigoureux du résidu de l'hydrolyse acide précédant l'attaque à la cellulase, ce fait implique des manipulations qui alourdissent la méthode. Plusieurs auteurs ont cependant proposé de faire agir la pepsine en première attaque (Jones \& Hayward, 1973 et 1975 ; Goto \& Minson, 1977 ; Allison \& Borzucki, 1978), mais aucun d'eux n'a fait état de la comparaison avec des résultats obtenus selon une séquence inverse ou bien avec d'autres enzymes protéolytiques.

Lorsque la préparation glucolytique est appliquée en premier, la pepsine permet d'obtenir de meilleurs résultats que la pronase (tabl. 7). Cette différence va dans le sens des résultats de Buchman (1979) qui a observé que la digestibilité des protéines des céréales par le rat était mieux prédite à l'aide des résultats d'une attaque pepsique que pronasique.

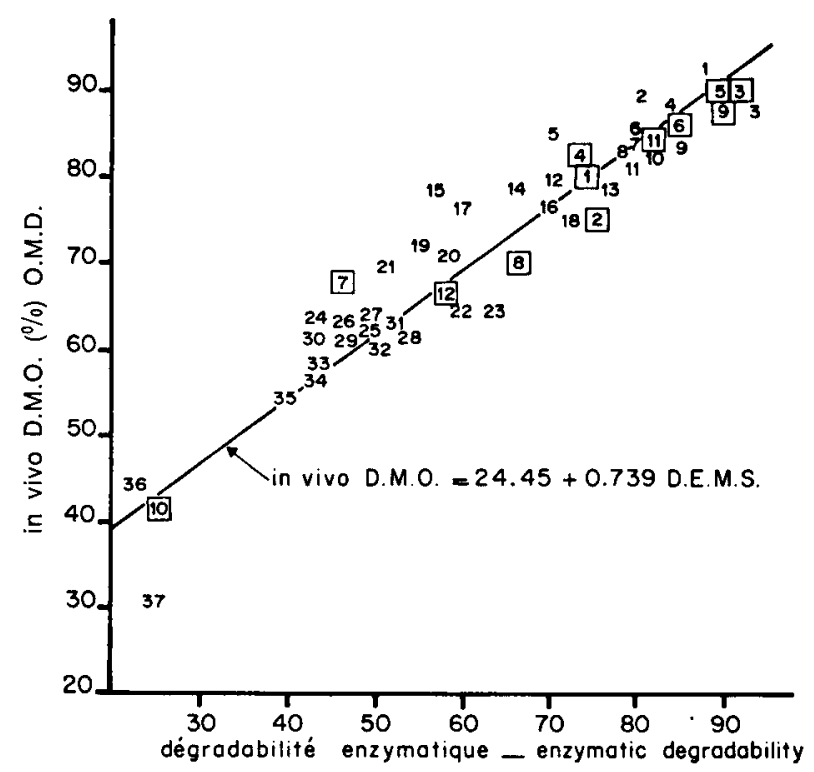

FIG. 3

Relation entre la digestibilité de la matière organique (D.M.O.) et la dégradabilité enzymatique de la matière sèche.

Relationship between organic matter digestibility (O.M.D.) and enzymatic dry matter degradability.

D.M.O. mesurée in vivo, numéros du tableau 10.

O.M.D. measured in vivo, numbers in table 10.

$\square$ D.M.O. des tables, numéros du tableau 7.

$\square$ O.M.D. values of the tables, numbers in table 7. 
Parmi les quatre combinaisons considérées, la séquence enzyme glucolytiquepepsine permet d'obtenir les meilleurs résultats. Cet enchaînement enzymes glucolytiques-pepsine a déjà été utilisé pour des tests enzymatiques (DONEFER et al., 1963 ; Guggolz et al., 1971 ; Mc QueEN \& van Soest, 1975 ; Kellner \& Kirchgessner, 1977). Il est également à rapprocher du protocole de travail de digestibilité in vitro proposé par Tilley \& TERRY (1963). La figure 3 traduit la relation entre le résultat de cette attaque et la digestibilité in vivo de la M.O. admise en moyenne pour les douze matières premières considérées. L'équation associant la digestibilité de la matière organique (tab1. 1) et la dégradabilité enzymatique rapportée à la matière sèche des aliments :

$$
\begin{gathered}
\text { D.M.O. }=0,6,686 \text { D.E.M.S. }+\underset{(\%)}{2 \%, 03} \\
(\mathrm{n}=12, \mathrm{R}=0,97, \mathrm{Sxy}=3,42) \quad \text { équation (1) }
\end{gathered}
$$

montre que les aliments sont plus discriminés les uns par rapport aux autres par la dégradabilité enzymatique que la digestibilité in vivo de la matière organique. D'autre part, l'étude des écarts à la régression semble indiquer que la dégradabilité enzymatique tend à sous-estimer la digestibilité des matières premières riches en cellulose facilement digestible : pellicules de soja, pulpe de betteraves.

Cette relation peut être considérée comme satisfaisante dans la mesure où, pour ces 12 matières premières, les corrélations entre les valeurs de digestibilité de la M.O. et les teneurs en cellulose brute, NDF, ADF et ADLignine sont respectivement de $-0,86,-0,84,-0,84,-0,55$. En outre, la combinaison entre les teneurs en cellulose brute et ADLignine, utilisée dans les équations de prévision de la valeur énergétique des mélanges concentrés (Sauvant, 1981) aboutit, pour les mêmes données, à un coefficient de corrélation multiple de 0,90 .

\section{TABleau 8}

Influence des variations de la durée de l'attaque à la pepsine après l'attaque aux enzymes glucolytiques sur la dégradabilité de la M.S. de quatre matières premières.

\begin{tabular}{|c|c|c|c|c|}
\hline $\begin{array}{l}\text { Matières premières } \\
\text { Ingredients }\end{array}$ & $12 \mathrm{mn}$ & $1 \mathrm{~h}$ & $2 \mathrm{~h}$ & $4 \mathrm{~h}$ \\
\hline $\begin{array}{l}\text { Tourteau de colza } \ldots \ldots \ldots \ldots \\
\text { Rapeseed meal }\end{array}$ & 73,0 & 73,8 & 74,7 & 74,8 \\
\hline $\begin{array}{l}\text { Tourteau de soja } \ldots \ldots \ldots \ldots \ldots \\
\text { Soyabean meal }\end{array}$ & 88,3 & 89,9 & 90,3 & 90,5 \\
\hline $\begin{array}{l}\text { Tourteau d'arachide } \ldots \ldots \ldots \ldots \ldots \\
\text { Peanut meal }\end{array}$ & 79,5 & 80,3 & 80,4 & 81,3 \\
\hline $\begin{array}{l}\text { Coques de soja } \ldots \ldots \ldots \ldots \ldots \ldots \\
\text { Soyabean hulls }\end{array}$ & 44,6 & 46,8 & 45,2 & 46,3 \\
\hline $\begin{array}{l}\text { Moyenne } \ldots \ldots \ldots \ldots \ldots \ldots \ldots \\
\text { Mean value }\end{array}$ & 71,34 & 72,69 & 72,71 & 73,24 \\
\hline
\end{tabular}

Influence of a variable duration of pepsin attack after glucolytic enzyme attack on dry matter degradability of four feed ingredients. 


\section{Essais de réduction de la durée de l'hydrolyse pepsique}

Pour chercher à explorer l'intérêt d'une réduction de la durée de l'attaque pepsique, un essai a été effectué sur quatre matières premières : les tourteaux de colza, soja et arachide et les pellicules de soja. Les écarts entre les valeurs de dégradabilité aux différents temps d'hydrolyse pris successivement sont faibles mais significatifs (tabl. 8). Les valeurs de dégradabilité obtenues en 4 heures se rapprochent le plus de la digestibilité moyenne connue de ces matières premières; ce résultat montre l'intérêt de conserver une durée d'hydrolyse pepsique de 4 heures.

\section{E. Description du protocole de la méthode retenue}

La méthode retenue pour réaliser des comparaisons ultérieures avec des tests in vivo ou d'autres méthodes de prédiction de la valeur énergétique comprend un empesage, l'action du cocktail d'enzymes glucolytiques suivie d'une attaque de $4 \mathrm{~h}$ à la pepsine chlorhydrique. Le protocole de travail correspondant à cette méthode est décrit dans le tableau 9. Cette méthode est rapide en comparaison des autres méthodes de dosage enzymatique qui comportent généralement deux traitements de 48 heures chacun (Goto \& Minson, 1977; IsRaElsen, ReXeN \& Thomsen, 1978) ou un de 24 heures et un de 48 heures (Jones \& HAYWARD, 1973 ; KEllner \& KirchGESSNER, 1977 ; CLARK \& BEARD, 1977). L'écart-type intra aliment de 0,53 p. 100 de dégradabilité indique que l'intervalle de confiance attaché à une valeur de dégradabilité est de $\pm 1,61$ p. 100 pour une mesure double et $\pm 0,97$ p. 100 pour une mesure triple.

Lorsque l'aliment considéré contient une proportion importante de lipides, la méthode peut aboutir à sous-estimer la valeur de la dégradabilité. Ainsi, pour des graines de lupin contenant un extrait éthéré de 7 p. 100 M.S. la dégradabilité est de 71,6 p. 100 sur le produit brut et de 94,3 p. 100 après délipidation (différence significative). Comme l'avaient déjà suggéré Saunders \& Hautala (1979), il est donc nécessaire de procéder à une délipidation dès que la matière première considérée a une teneur en extrait éthéré supérieure à $7-8$ p. 100.

\section{F. Mise en cuvre pratique de la méthode dans les laboratoires}

Une chaîne analytique a été récemment organisée au niveau de la C.E.E. (vaN DER MEer, 1982) pour tester trois méthodes de dégradabilité enzymatique sur 15 aliments, cités au tableau 10, dont la digestibilité in vivo de la matière organique est connue. Une des trois méthodes correspond à celle qui est décrite dans la présente communication : trente-quatre laboratoires ont participé à ce test. L'écart-type intralaboratoire (répétabilité) est de 1,34 p. 100, la valeur moyenne de l'écart-type global (reproductibilité) est de 4,24 p. 100 ; cette valeur varie entre 2,75 p. 100 et 5,85 p. 100 selon l'aliment considéré (VAN DER MEer, 1984). A partir des résultats obtenus, nous avons calculé que les séries de valeurs de dégradabilité fournies par les différents laboratoires étaient très corrélées aux valeurs de digestibilité in vivo. En effet, 27 coefficients de corrélation sur 34 sont supérieurs ou égaux à $0,95,32$ sont compris entre 0,92 et 0,97 , les coefficients des deux autres laboratoires étant égaux à 0,87 et 0,63 respectivement. 


\section{Tableau 9}

Protocole de travail de la méthode.

Working method.

1. Pesée de $0,5 \mathrm{~g}$ d'échantillon dans un tube à centrifuger de $100 \mathrm{ml}$. Weighing of a $0.5 \mathrm{~g}$ sample in a $100 \mathrm{ml}$ centrifugation tube.

2. a. Empesage à $70^{\circ} \mathrm{C}$ pendant $10 \mathrm{mn}$ dans $25 \mathrm{ml}$ d'eau distillée. Starching at $70^{\circ} \mathrm{C}$ for $10 \mathrm{~min}$ in $25 \mathrm{ml}$ distillated water.

b. Refroidissement à température ambiante.

Cooling at room temperature.

3. a. Adjonction de $25 \mathrm{ml}$ de la solution enzymatique (1). Bouchage des tubes. Addition of $25 \mathrm{ml}$ enzymatic solution (1). Tubes sealing.

b. Agitation lente : une fois avant incubation et deux fois pendant incubation. Slow stirring, once before and twice during incubation.

c. Incubation dans un bain marie thermostaté à $39 \pm 1$ "C. Incubation in a thermostated water bath $\left(39 \pm 1^{\circ} \mathrm{C}\right)$.

4. a. Centrifugation de $10 \mathrm{mn}$ à 3000 tours, après avoir complété à $100 \mathrm{ml}$ avec de l'eau chaude.

Centrifugation for $10 \mathrm{~min}$ at $3000 \mathrm{t}$. after filling up to $100 \mathrm{ml}$ hot water.

b. Prélèvement du surnageant.

Removal of supernatant.

5. a. Adjonction de $50 \mathrm{ml}$ de la solution pepsine-chlorhydrique (2). Bouchage des tubes. Addition of $50 \mathrm{ml}$ pepsin-hydrochloric solution (2). Tubes sealing.

b. Agitation lente avant incubation. Slow stirring before incubation.

c. Incubation des tubes pendant 4 heures à $39^{\circ} \mathrm{C}$. Incubation of tubes for 4 h at $39^{\circ} \mathrm{C}$.

6. a. Centrifugation de $10 \mathrm{mn}$ à 3000 tours. Centrifugation for $10 \mathrm{~min}$ at $3000 \mathrm{t}$.

b. Filtration sur un creuset de verre fritté (porosité 2). Filtration on a sintered glass crucible (porosity 2).

c. Nettoyage du résidu à l'eau chaude, jusqu’à neutralisation vérifiéc au papier pH. Cleaning of the residue with hot water until neutralization checked on $p H$ paper.

7. a. Séchage au four à $103{ }^{\circ} \mathrm{C}$ pendant 8 heures au moins. Pesée. Oven drying at $103^{\circ} \mathrm{C}$ for at least $8 \mathrm{~h}$. Weighing.

b. Minéralisation au four, $550^{\circ} \mathrm{C}$ pendant 3 heures. Pesée. Mineralization in the oven at $550^{\circ} \mathrm{C}$ for $3 \mathrm{~h}$. Weighing.

(1) Tampon acétate : 6,8 g d'acétate de $\mathrm{Na}+2,9 \mathrm{mI}$ d'acide acétique concentré par litre. Concentrations de $1,6 \mathrm{~g} / 1,2 \mathrm{~g} / 1,3 \mathrm{~g} / \mathrm{l}$ pour l'amylase A 6505 , la cellulase SP 122 et l'hémicellulase respectivement.

Acetate buffer : $6.8 \mathrm{~g} \mathrm{Na}$ acetate $+2.9 \mathrm{ml}$ concentrated acetic acid per 1 .

Concentrations of $1.6 \mathrm{~g} / \mathrm{l}, 2 \mathrm{~g} / \mathrm{l}, 3 \mathrm{~g} / \mathrm{l}$ for amylase $A 6505$, cellulase $S P \mathrm{I22}$, hemicellulase respectively.

(2) $51,6 \mathrm{ml}$ d'acide chlorhydrique concentré complété à $1 \mathrm{I}$. Dissolution de $2 \mathrm{~g}$ de pepsine $/ 1$. $51.6 \mathrm{ml}$ concentrated hydrochloric acid brought to $l \mathrm{l}$. Dissolution of $2 \mathrm{~g}$ of pepsine $/ \mathrm{l}$. 


\section{G. Prédiction de la digestibilité mesurée in vivo de la matière organique}

La méthode décrite a été appliquée, ainsi que les analyses chimiques des teneurs en cellulose brute, NDF, ADF et ADLignine, à 37 aliments dont la digestibilité in vivo de la matière organique avait été mesurée expérimentalement au laboratoire (18), au centre de Lelystad (15) ou au laboratoire des aliments de Theix (4). Les valeurs des différentes caractéristiques considérées sont rapportées dans le tableau 10. Les patentiels de prédiction de la digestibilité de la M.O. ont été comparés sur trois ensembles de ces aliments : la totalité $(\mathrm{n}=37)$, les aliments concentrés composés ou non, en incluant les drèches de brasserie $(n=18)$ et les aliments composés $(n=11)$.

La teneur en cellulose brute et les critères analytiques de Van Soest, considérés individuellement, sont pour les 37 aliments de moins bons prédicteurs de la digestibilité de la M.O. que la dégradabilité enzymatique (tabl. 11). Par contre, la combinaison des teneurs en NDF et ADLignine aboutit à une prédiction de qualité légèrement supérieure à celle de la dégradabilité enzymatique.

Les coefficients de l'équation de la prévision de la digestibilité de la M.O. (DMO) de l'ensemble des 37 aliments à partir de la dégradabilité enzymatique :

$$
\mathrm{DMO}=24,45+0,739 \text { DEMS } \quad(\mathrm{R}=0,931, \text { Sxy }=4,97)
$$

sont très comparables à ceux de l'équation (1). La figure 3 (cf. p. 279) traduit, en outre, l'absence de discrimination entre la population des 12 aliments du tableau 7 utilisés pour calculer l'équation (1) et celle des 37 aliments présentement évoqués.

Lorsque les 18 aliments concentrés, composés ou non, sont considérés, les valeurs des écarts-types résiduels sont plus faibles que celles observées pour l'ensemble des 37 aliments (tabl. 11). La dégradabilité enzymatique est, pour ces aliments, le meilleur critère de prédiction de la valeur de la digestibilité de la M.O. Les teneurs en cellulose brute, NDF et ADF, présentent des biais communs lorsqu'elles sont utilisées pour prédire la digestibilité de la M.O. des aliments concentrés : sous-estimation pour les pulpes de betteraves $(\simeq 8$ points) et d'agrumes $(\simeq 8$ points $)$, de la farine de maïs $(\simeq 6$ points $)$, sur-estimation pour les drèches de brasserie $(\simeq 9$ et 16 points pour les $n^{0 . s} 21$ et 24 respectivement) et le mélange $n^{\circ} 22(\simeq 12,5$ points) riche en paroi végétale peu digestible. Les valeurs des écarts-types résiduels des prédictions des aliments concentrés à partir de la dégradabilité enzymatique et de la combinaison NDF, ADLignine sont comparables (tabl. 11). Par contre, les valeurs individuelles des écarts aux modèles correspondants ne sont absolument pas corrélées, ce qui indique que ces deux types de prédicteurs ne présentent pas les mêmes biais pour les 18 aliments considérés. Cet examen des écarts individuels ne permet cependant pas d'avancer une hypothèse sur l'origine de ce biais.

L'ajustement des 11 résultats de digestibilité de la MO des aliments composés à partir de la dégradabilité enzymatique aboutit à un modèle tout à fait comparable, en terme de coefficients de régression et de précision, à ce qui a été obtenu pour l'ensemble des aliments concentrés (tabl. 1). Par contre, la teneur en ADLignine devient un meilleur prédicteur pour ces aliments puisque l'écart-type résiduel n'est que de 2,06 p. 100 de digestibilté. La combinaison des teneurs en NDF et ADLignine ne permet pas d'améliorer la qualité de la prédiction. 


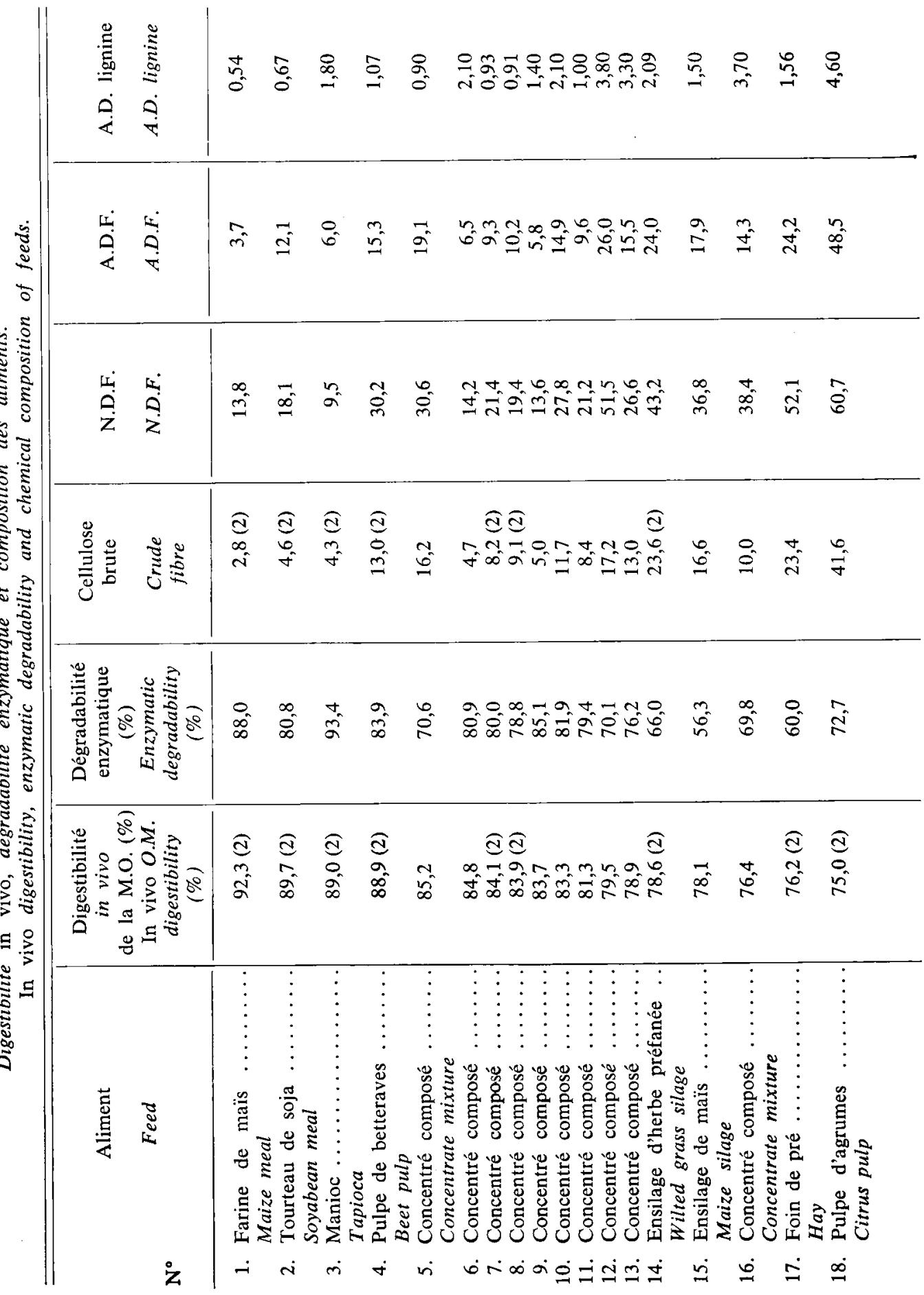




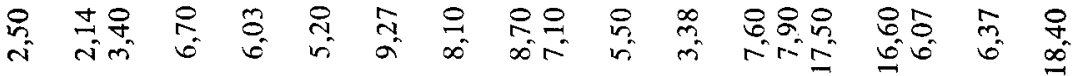

节

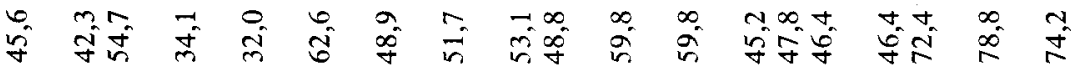

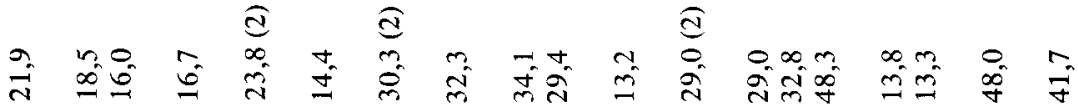

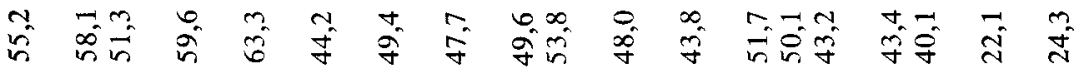

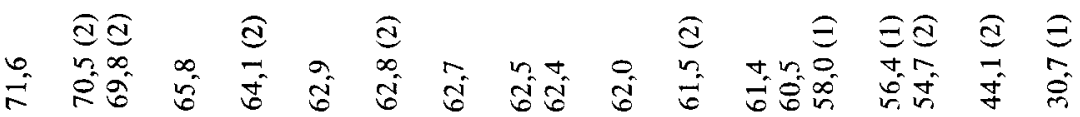

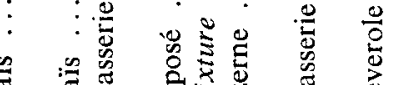

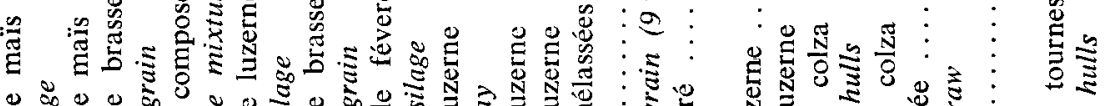

\&

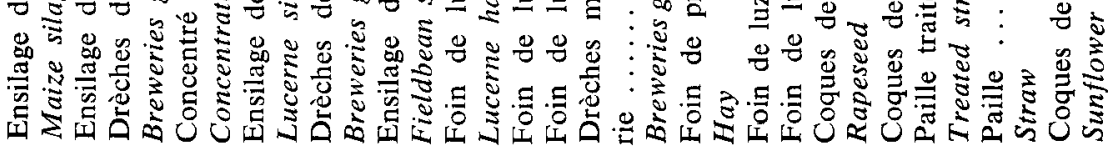

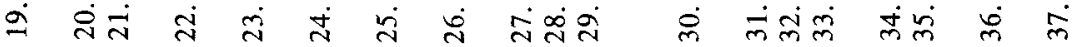


A. CASTAGNA et al.

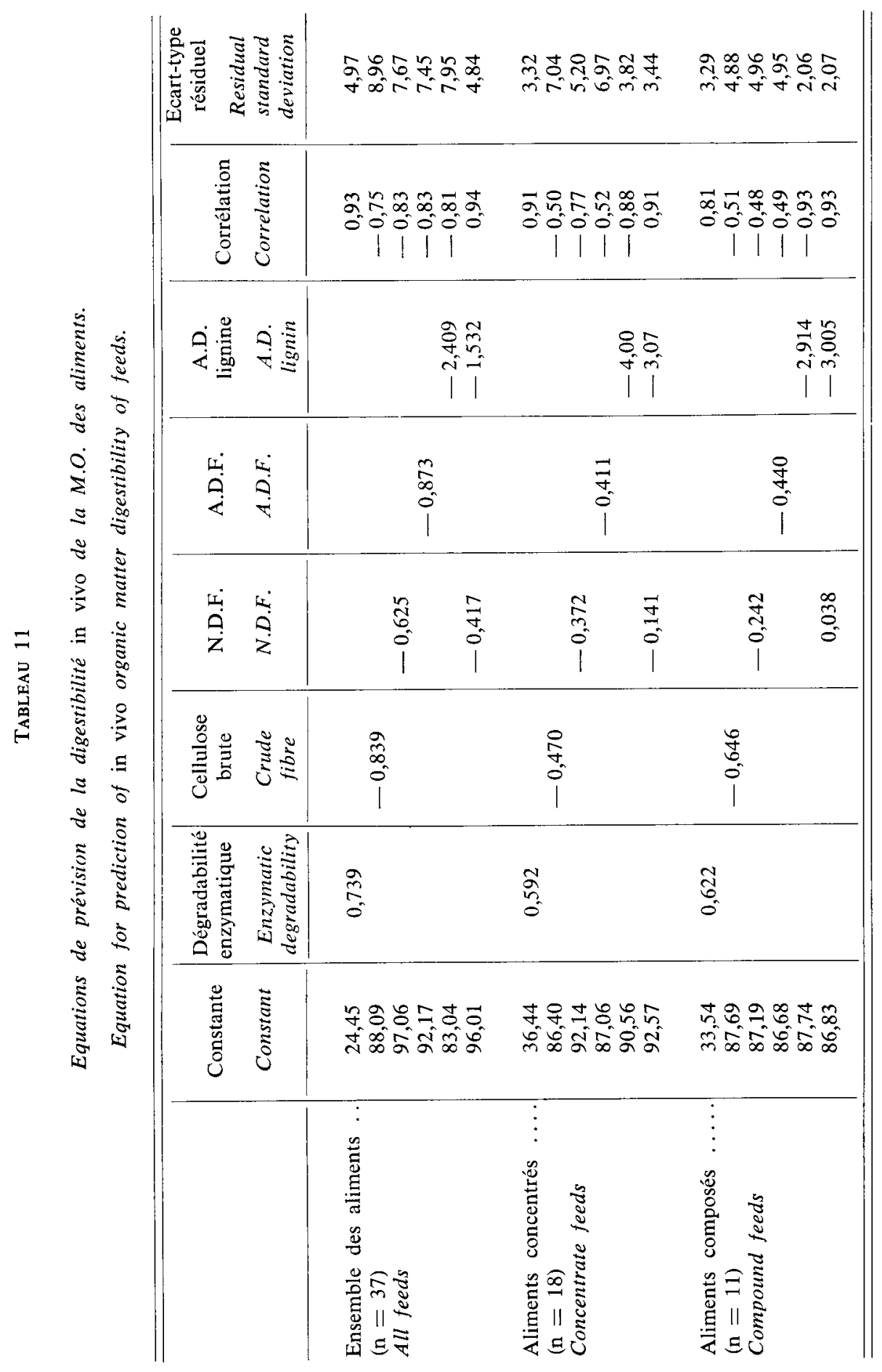




\section{Conclusions}

Ce travail ne prétend pas être exhaustif vis-à-vis des nombreuses préparations enzymatiques utilisables ainsi que de la multiplicité des combinaisons possibles de ces préparations et des choix des conditions physico-chimiques des incubations. Ces résultats montrent cependant qu'en partant d'un nombre restreint de préparations enzymatiques fréquemment utilisées, il est possible d'aboutir à une méthode dont les résultats sont d'emblée applicables et incitent la poursuite des travaux dans ce domaine.

La méthode retenue s'apparente à celles qui ont été proposées par ABE, HoriI \& Kaмeока (1979) et par Dowman \& Collins (1982). Elle s'en distingue en réalité nettement par sa simplicité d'application. Les résultats présents montrent, en particulier, qu'il est possible d'éviter les transvasements d'échantillons et de mélanger des préparations enzymatiques glucolytiques pour aboutir à une méthode de prévision de la digestibilité de la matière organique des aliments concentrés et sous-produits assimilés qui soit applicable à grande échelle.

Les résultats obtenus par 34 laboratoires de la C.E.E., appliquant pour la première fois la méthode, sont encourageants par la qualité de la prédiction intralaboratoire. Cependant, les écarts systématiques de niveau de dégradabilité, observés entre laboratoires, plaident pour l'emploi, dans chaque incubation, d'un même échantillon standard dont la digestibilité in vivo de la M.O. est, si possible, connue. Ce standard pourrait, en outre, permettre de corriger, en partie au moins, des variations d'activité entre livraisons de préparations enzymatiques.

Une des principales limites de ce travail vient du fait que les valeurs de digestibilité de la matière organique prises comme référence dans la phase de mise au point n'ont pas été mesurées in vivo mais correspondent aux valeurs les plus probables généralement admises. Cependant, les matières premières utilisées présentaient des caractéristiques analytiques proches des valeurs moyennes connues, d'autre part la digestibilité de la M.O. d'un aliment concentré peut varier notablement selon les conditions expérimentales extrinsèques (fourrage de base, niveau alimentaire...) et la méthode de calcul de cette digestibilité (GIGER \& SAUvanT, 1982). Cette incertitude demeure importante pour une même technique appliquée au sein d'un seul laboratoire. Ainsi pour les 6 aliments concentrés dont la digestibilité de la M.O. a été mesurée à Lelystad, l'écart-type des résultats obtenus est, en moyenne, de 1,6 p. 100, ce qui signifie que 95 p. 100 de ces résultats sont compris dans une plage présentant une amplitude de 6,4 p. 100 de digestibilité de la M.O. Pour ces raisons, des valeurs moyennes ont semblé préférables dans la première phase du travail.

Lorsque les valeurs les plus probables de digestibilité de la M.O. sont considérées, la dégradabilité enzymatique est la meilleure caractéristique unique pour les prévoir. Ces résultats sont proches de ceux mentionnés par GugGolz et al. (1971) qui ont utilisé comme référence les valeurs T.D.N. les plus probables de 24 aliments expérimentaux. Lorsque l'ensemble des aliments, ou les 18 concentrés, ayant fait l'objet d'une mesure in vivo de digestibilité de la M.O. est considéré, la cellulose brute et les critères analytiques de Van Soest pris individuellement sont également de moins bons prédicteurs de la digestibilité que la dégradabilité enzymatique, ce qui rejoint les résultats observés pour des aliments composés par AERTs et al. (1981) et Wainman, Dewey \& Boyne (1981). Cependant, présentement, la combinaison des 
teneurs en NDF et ADLignine aboutit à une précision de prédiction légèrement supérieure à celle de la dégradabilité enzymatique. En outre, pour les 11 aliments composés, la teneur en ADLignine aboutit aux meilleurs résultats. SAUvant (1981) et WaINMAN, DeWEY \& Boyne (1981) ont déjà remarqué l'intérêt de la combinaison des teneurs en NDF et ADLignine pour prévoir la digestibilité ou la valeur énergétique des aliments concentrés. Pour les résultats du Rowett, ces deux critères associés à la teneur en extrait éthéré sont également de meilleurs prédicteurs de la teneur en énergie métabolisable de 24 aliments concentrés que la teneur en extrait éthéré associée à la dégradabilité enzymatique par la méthode de Dowman \& Collins (1982).

Ces différents résultats montrent que d'autres investigations devront être conduites pour comparer les intérêts respectifs de la méthode de Van Soest et de la dégradabilité enzymatique pour prévoir la digestibilité des aliments concentrés et sousproduits assimilés. Ces deux méthodes doivent, en outre, être confrontées à d'autres. Ainsi, Aerts et al. (1981) ont abouti à de meilleures prédictions de la valeur énergétique de 32 aliments composés par des mesures de digestibilité in vitro ou in sacco qu'avec la dégradabilité enzymatique ou les teneurs en cellulose brute, NDF, ADF considérées séparément. Par contre Wainman, Dewey \& Boyne (1981) ont obtenu une prédiction inférieure en appliquant la digestibilité in vitro.

L'utilisation de préparations enzymatiques présente l'avantage de ne pas nécessiter de dosage chimique et d'éviter l'entretien d'animaux fistulés donneurs de jus de rumen. Son inconvénient majeur, par rapport aux méthodes chimiques, réside dans la durée d'application et la régularité de la production et de l'activité des préparations enzymatiques actuellement commercialisées. Cependant, la simplicité des appareils utilisés et de la conduite des mesures de laboratoire devrait permettre de compenser cette durée grâce à la possibilté d'analyser simultanément un nombre important d'échantillons.

\section{Summary}

\section{Study of the enzymatic degradability of concentrates and by-products}

A method of enzymatic degradability measurement was elaborated to be valuable for concentrate feedstuffs and to be as simple as possible. The method was based on three main steps : an aqueous hydrolysis - an incubation in a glucolytic enzyme (amylase, cellulase, hemicellulase) mixture - an incubation in a pepsin chlorhydric buffer. When considering 37 feedstuffs of different origins $(2.8 \leqslant$ crude fibre $\leqslant 48.3$ p. 100 of $\mathrm{DM})$ with in vivo measured values of organic matter digestibility $(30.7 \leqslant$ OMD $\leqslant 92.3$ p. 100$)$, the enzymatic degradability allowed to predict more accurately the feed OMD than the separate data of crude fibre, NDF, ADF and AD lignin contents. A similar observation remained valuable when the 18 concentrates feedstuffs were considered separately. The combination of the NDF and ADLignin contents allowed to obtain a precision similar to the enzymatic degradability for the $37(\mathrm{RSD}=4.84 \mathrm{p} .100$ vs $4.97 \mathrm{p} .100)$ or the $18(\mathrm{RSD}=3.44$ vs 3.32) above mentioned feeds. When considering the 11 compound feeds, the ADLignin content gave the best prevision ( $R S D=2.06$ vs 3.29 p. 100). The described method was tested into an EEC ring-test.

Key-words : Enzymatic degradability, concentrates, by-products, digestibility prediction, Van Soest analysis.

Reçu en septembre 1982.

Accepté en avril 1984. 


\section{Références bibliographiques}

AbE A., Horir S., Kameoka K.I., 1979. Development and application of cellulase hydrolysis for predicting digestibility of roughage. 1. - Digestion of cell wall carbohydrates by cellulase. Jap. J. Zootechn. Sci., 43, 141-145.

Abe A., Hori S., KameoKa K., 1979. Application of enzymatic analysis with gluco-amylase, pronase and cellulase to various feeds for cattle. J. Anim. Sci., 48, 1483-1490.

Aerts J.V., Cottyn B.G., de Brabander D.L., Moermans R.J., Buysse F.X., 1981. Prediction of the net energy value of concentrate mixtures for dairy cattle, 32th Annual E.A.A.P. Meeting, Zagreb.

Allison M., Borzucki R., 1978. - Cellulase methods for the efficient digestion of grasses and brassicas. J. Sci. Food. Agric., 29, 293-297.

ANDRIEU J.P., 1979. Utilisation d'enzymes cellulolytiques pour prévoir la valeur nutritive des aliments pour les ruminants. D.E.A., Université de Clermont II, U.E.R. des Sciences exactes et naturelles, 40 pages.

Aufrere J., 1982. Etude de la prévision de la digestibilité des fourrages par une méthode enzymatique. Ann. Zootech., 31, 111-130.

BuchmanN N.B., 1979. In vitro digestibility of protein from Barley and other Cereals. J. Sci. Food Agric., 30, 583-589.

Clark J., Beard J., 1977. Prediction of the digestibility of ruminant feeds from their solubility in enzyme solutions. Anim. Feed Sci. Technol., 2, 153-159.

Demarquilly C., Andrieu J., Sauvant D., 1978. Chapitre 17 : Tableaux de la valeur nutritive des aliments. In : L'alimentation des ruminants. I.N.R.A. Publications, route de Saint-Cyr, 78000 Versailles.

Dowman M.G., Collins F., 1982. The use of enzymes to predict the digestibility of animal feeds. J. Sci. Food Agric., 33, 689-696.

Donefer E., Niemann P.J., Crampton E.W., Llyod L.E., 1963. Dry matter disappearance by enzyme and aqueous solution to predict the nutritive value of forages. J. Dairy Sci., 46, 965-969.

Giger S., Dorleans M., Sauvant D., 1979. Adaptation of the Van Soest method to a routine determination of concentrate feedstuffs, 30th meeting E.A.A.P., Harrogate.

Giger S., Sauvant D., 1982. Comparaison de différentes méthodes d'évaluation de la digestibilité des aliments concentrés par le ruminant. Ann. Zootech., 32, 83-113.

Goto I., Minson D.J., 1977. Prediction of the dry matter digestibility of tropical grasses using a pepsin-cellulase assay. Anim. Feed Sci. Technol., 2, 247-253.

Guggolz J., Saunders R.M., Kohler G.D., Klopfenstein T.J., 1971. Enzymatic evaluation of processes for improving agricultural wastes for ruminants feeds. J. Anim. Sci., 33, $167-170$.

Israelsen M., Rexen B., Thomsen V.K., 1978. Cellulase insoluble fibre as a measure of unavailable organic matter in cattle compounds containing alkali-treated straw. Anim. Feed Sci. Technol., 3, 227-234.

JARRige R., Thivend P., 1969. Action d'une cellulase fongique sur les membranes et son intérêt pour prévoir la digestibilité des plantes fourragères. Ann. Biol. Anim. Biochim. Biophys., 9, 171-190.

Jones D.I.H., HaYward M.V., 1973. A cellulase digestion technique for predicting the dry matter digestibility of grasses. J. Sci. Food Agric., 24, 1419-1426.

JoNes D.I.L., Hayward M.V., 1975. The effect of pepsin treatment of herbage on the prediction of dry matter digestibility in fungal cellulase solution. J. Sci. Food Agric., 26, 711 .

Kellner R.J., Kirchgessner P.M., 1977. Estimation of forage digestibility by a cellulase method. Z. Tierphysiol. Tierernähr. Futtermittelkde, 39, 9-16.

Mc Queen R., VAn Soest P.J., 1975. Fungal cellulase and hemicellulase prediction of forage digestibility. J. Dairy Sci., 58, 1482-1491. 
ROBERTSON J.B., VAN SOEST P.J., 1977. Dietary fiber estimation in concentrate feedstuffs. 69th meeting of the American Society of Animal Science, University of Wisconsin, Madison, July 23-27, 1977.

Roughan R., Holland M., 1977. Prediction in vivo digestibilities of herbages by exhaustive enzymic hydrolysis of cell walls. J. Sci. Food Agric., 28, 1057-1064.

Saunders R.M., Hautala E., 1979. Dietary fiber evaluation of wheat products by in vitro and in vivo methods. Dietary fibers : chemistry and nutrition, ed by Inglett and Falkehag. Acad. Press, New York - San Francisco - London, p. 79-92.

Sauvant D., 1981. Prévision de la valeur énergétique des aliments concentrés et composés pour les ruminants. In : La prévision de la valeur nutritive des aliments des ruminants, Versailles, I.N.R.A., p. 237-258.

Tili.ey J.M.A., Terry R.A., 1963. A two stage technique for the in vitro digestion of forage crops. J. Br. Grassld. Soc., 18, 104-111.

VAN Der MeER J.M., 1982. Manual of the C.E.C. « in vitro ring test », I.V.V.O., Lelystad, Netherlands, 23 pages.

VAN DER MeER J.M., 1983. Statistical report of the C.E.C. " in vitro ring test », Report $\mathrm{n}^{\circ} 155$, I.V.V.O., Lelystad, Netherlands, 36 pages.

VAN Soest P.J., WINe R.H., 1967. Use of detergents in the analysis of fibrous feeds. IV. - Determination of plant cell wall constituents. J. Assoc. Off. Acad. Chem., 50, 50-55.

Wainman F.W., Dewey P.J.S., Boyne A.N., 1981. Feedingstuffs Evaluation Unit Third report, Rowett Research Institute. 